\title{
Drug-Drug Interaction Potential of Darolutamide: In Vitro and Clinical Studies
}

\author{
Christian Zurth $^{1}$ (1) $\cdot$ Mikko Koskinen $^{2} \cdot$ Robert Fricke $^{3} \cdot$ Olaf Prien $^{1} \cdot$ Timo Korjamo $^{2} \cdot$ Kristina Graudenz $^{1}$. \\ Karsten Denner ${ }^{1} \cdot$ Michaela Bairlein $^{3} \cdot$ Clemens-Jeremias von Bühler $^{3} \cdot$ Gary Wilkinson $^{1} \cdot$ Hille Gieschen ${ }^{1}$
}

Published online: 30 September 2019

(c) The Author(s) 2019

\begin{abstract}
Background and Objectives Darolutamide is a novel androgen receptor (AR) antagonist approved for the treatment of nonmetastatic castration-resistant prostate cancer (nmCRPC). Accordingly, the drug-drug interaction (DDI) potential of darolutamide was investigated in both nonclinical and clinical studies.

Methods In vitro studies were performed to determine the potential for darolutamide to be a substrate, inducer or inhibitor for cytochrome P450 (CYP) isoforms, other metabolizing enzymes and drug transporters. A phase I drug-interaction study in healthy volunteers evaluated the impact of co-administering rifampicin [CYP3A4 and P-glycoprotein (P-gp) inducer] and itraconazole [CYP3A4, P-gp and breast cancer resistance protein (BCRP) inhibitor] on the pharmacokinetics of darolutamide. Two further phase I studies assessed the impact of co-administering oral darolutamide on the pharmacokinetics of midazolam (sensitive CYP3A4 substrate) and dabigatran etexilate (P-gp substrate) and the impact on the pharmacokinetics of co-administered rosuvastatin [a substrate for BCRP, organic anion-transporting polypeptide (OATP)1B1, OATP1B3 and organic anion transporter (OAT)3].

Results In vitro, darolutamide was predominantly metabolized via oxidative biotransformation catalyzed by CYP3A4 and was identified as a substrate for P-gp and BCRP. The enzymatic activity of nine CYP isoforms was not inhibited or slightly inhibited in vitro with darolutamide, and a rank order and mechanistic static assessment indicated that risk of clinically relevant DDIs via CYP inhibition is very low. In vitro, darolutamide exhibited no relevant induction of CYP1A2 or CYP2B6 activity. Inhibition of BCRP-, P-gp-, OAT3-, MATE1-, MATE2-K-, OATP1B1- and OATP1B3-mediated transport was observed in vitro. Phase I data showed that darolutamide exposure increased 1.75 -fold with co-administered itraconazole and decreased by $72 \%$ with rifampicin. Co-administration of darolutamide with CYP3A4/P-gp substrates showed no effect or only minor effects. Rosuvastatin exposure increased 5.2-fold with darolutamide because of BCRP and probably also OATPB1/OATPB3 inhibition.

Conclusions Darolutamide has a low potential for clinically relevant DDIs with drugs that are substrates for CYP or P-gp; increased exposure of BCRP and probably OATP substrates was the main interaction of note.
\end{abstract}

\section{Introduction}

Darolutamide is a novel androgen receptor (AR) antagonist recently approved for the treatment of nonmetastatic

Electronic supplementary material The online version of this article (https://doi.org/10.1007/s13318-019-00577-5) contains supplementary material, which is available to authorized users.

Enhanced digital features To view enhanced digital features for this article go to https://doi.org/10.6084/m9.figshare.9896855.

Christian Zurth

christian.zurth@bayer.com

Extended author information available on the last page of the article castration-resistant prostate cancer (nmCRPC) [1-3]. In phase I and II clinical studies in metastatic castrationresistant prostate cancer (mCRPC), darolutamide demonstrated significant antitumor activity and a good safety profile $[4,5]$. Significant improvement in metastasis-free survival was demonstrated for darolutamide compared with placebo, with a safety profile similar to that of androgen deprivation therapy alone in the phase III ARAMIS trial in patients with nmCRPC [6]. A phase III trial (ARASENS) in metastatic hormone-sensitive prostate cancer is ongoing (NCT02799602).

Darolutamide is structurally distinct from other AR inhibitors [7] and comprises two pharmacologically active diastereomers, $(S, R)$-darolutamide and $(S, S)$-darolutamide. 


\section{Key points}

In a number of clinical and preclinical studies, darolutamide demonstrated a low potential to interact with co-administered medications that affect or are affected by enzymes or transporters involved in drug metabolism.

The potential for darolutamide to increase the exposure of drugs eliminated by the efflux transporter, breast cancer resistance protein, appears to be a clinically relevant drug-drug interaction (DDI).

A low potential for DDIs is important when treating prostate cancer patients, who are generally receiving additional medications for other medical conditions.

The major metabolite, keto-darolutamide, exhibits similar pharmacologic activity in vitro [1, 7], but has a 40-fold lower fraction unbound in human plasma compared with darolutamide [3], and it is therefore of lower relevance in terms of mediating efficacy and potential drug interactions. Nonclinical studies have demonstrated that darolutamide acts by potently blocking AR signaling and inhibiting testosterone-induced nuclear translocation of AR in prostate cancer cells, leading to impaired tumor growth and survival [7]. In contrast to AR inhibitors currently approved for the treatment of nmCRPC, darolutamide shows low penetration of the blood-brain barrier in rodents, which may explain the observed lower propensity for central nervous system (CNS) effects compared with the approved AR inhibitors, and does not increase serum testosterone levels [6-9].

As patients with nmCRPC are typically older men with multiple comorbidities requiring concomitant medications [10], it is important to evaluate the drug-drug interaction (DDI) potential of novel anticancer therapies. This information is also requested by health authorities worldwide, including the US Food and Drug Administration (FDA) and European Medicines Agency (EMA) [11-13]. Hence, in vitro and phase I clinical evaluations have been conducted to elucidate whether darolutamide is a clinically significant substrate, inhibitor or inducer for relevant drug-metabolizing enzymes or transporters.

\section{Subjects and Methods}

\subsection{In Vitro Studies}

\subsubsection{Test Compounds and Materials}

Darolutamide, $(S, R)$-darolutamide, $(S, S)$-darolutamide, and keto-darolutamide were prepared at Orion Pharma (Finland),
Bayer Pharma AG (Germany), or Fermion Oy (Finland). Suppliers of other materials used in the in vitro assays are listed in Table S1. Further details of in vitro materials and methods can be requested from Bayer Pharma AG.

\subsubsection{Substrate Characteristics for Drug Metabolizing Enzymes}

Darolutamide, both diastereomers and its active metabolite were incubated in male human hepatocytes, liver cytosol and liver microsomes, recombinant cytochrome P450 (CYP) and recombinant aldo-keto reductase (AKR) isoforms to identify the enzymes involved in phase I metabolism. Similarly, darolutamide and both diastereomers were incubated with human liver, kidney and intestinal microsomes fortified with uridine 5'-diphospho-glucuronic acid (UDPGA) and a panel of 13 recombinant uridine-diphosphate glucuronosyltransferase (UGT) isoforms (Supersomes ${ }^{\mathrm{TM}}$ ) to elucidate the role and tissue localization of glucuronidation in darolutamide biotransformation. Experiments were performed in the presence or absence of enzyme-selective chemical inhibitors in pooled human liver microsomes to determine the relevance of individual pathways.

\subsubsection{Substrate Characteristics for Drug Transporters}

Substrate characteristics of darolutamide and keto-darolutamide for the efflux transporters P-glycoprotein (P-gp) and breast cancer resistance protein (BCRP) were investigated using wildtype human colon adenocarcinoma (Caco-2) cells and proprietary cell lines that have reduced expression of human BCRP (CPT-B1 cells) or P-gp (CPT-P1 cells). Probe substrates and reference inhibitors (Table 1) were used for positive and negative controls, respectively, to determine efflux ratios. Assessment of darolutamide and keto-darolutamide as BCRP substrates was also conducted in BCRPMadin-Darby Canine Kidney (BCRP-MDCK) cells.

The substrate potential of darolutamide and keto-darolutamide for the uptake transporters organic anion-transporting polypeptide (OATP)1B1, OATP1B3 and organic cation transporter (OCT) 1 was evaluated in a cellular uptake assay in transfected human embryonic kidney (HEK) cells overexpressing the respective transporter, run in parallel with vector-control cells. Standard inhibitors and probe substrates were used (Table 1).

\subsubsection{Inhibitory Potential of Darolutamide for CYP and UGT Isoforms}

The inhibitory potential of darolutamide, both diastereomers and keto-darolutamide for CYP1A2, 2A6, 2B6, 2C8, 2C9, $2 \mathrm{C} 19,2 \mathrm{D} 6,2 \mathrm{E} 1$ and $3 \mathrm{~A} 4$ was assessed at concentrations of $0.03-100 \mu \mathrm{M}$ in human liver microsomes using standard 
substrates (Table 2). The rank order approach and mechanistic static model suggested by the US FDA and EMA were applied to evaluate the DDI risk with darolutamide through CYP inhibition [12, 14]. The inhibition of UGT1A1, 1A4, 1A6, 1A9 and 2B7 by both diastereomers and keto-darolutamide was investigated by assessing the glucuronidation of UGT-selective substrates in human liver microsomes and using a rank order approach. CYP or UGT substrates were incubated in the presence and absence of darolutamide and/ or its diastereomers, and keto-darolutamide, and parallel incubations with standard inhibitors for each enzyme were performed as positive controls. Time-dependent inhibition of CYP3A4 by darolutamide, its diastereomers and ketodarolutamide was evaluated after 30 min pre-incubation.

\subsubsection{Induction Potential of Darolutamide for CYP Isoforms}

Induction of CYP1A2, CYP2B6 and CYP3A4 by darolutamide, its diastereomers and keto-darolutamide was assessed at concentrations of $0.005-10 \mathrm{mg} / \mathrm{l}$ (approximately $0.0126-25 \mu \mathrm{M}$ ) in primary-cultured human hepatocytes from three donors. After 3 consecutive days of dosing with vehicle control, negative control (penicillin), test compound or CYP inducers, the hepatocytes were incubated with selective marker substrates (Table 2) to analyze the effects on CYP activity. The positive control inducers used were omeprazole (CYP1A2), phenobarbital (CYP2B6), rifampicin (strong CYP3A4 inducer), bosentan (moderate CYP3A4 inducer) and pioglitazone (weak CYP3A4 inducer). To assess the potential risk for CYP3A4 induction in the clinic, the relative induction score (RIS) method [12] was applied to describe the DDI potential of darolutamide, its diastereomers and keto-darolutamide.

\subsubsection{Inhibitory Potential of Darolutamide for Drug Transporters}

Inhibition of the efflux transporters, P-gp and BCRP, by darolutamide at concentrations of $0.25-60 \mu \mathrm{M}$ was assessed in Caco- 2 cells using standard probe substrates and controls (Table 1). P-gp and BCRP inhibition by keto-darolutamide at concentrations of $0.0412-10 \mu \mathrm{M}$ was assessed in MDCK cells. Inhibition of bile salt export pump (BSEP) was evaluated in sandwich-cultured human hepatocytes, and multiresistance protein (MRP)2, MATE1 and MATE2-K were evaluated in transfected HEK cells using selective probe substrates and reference inhibitors (Table 1). Probe substrate transport was assessed in the absence and presence of darolutamide and keto-darolutamide, and the concentrations required for $50 \%$ inhibition $\left(\mathrm{IC}_{50}\right.$ ) values were determined.

Inhibition of hepatic uptake transporter proteins OATP1B1, OATP1B3, organic anion transporter (OAT)1, OAT3, OCT1, OCT2, $\mathrm{Na}^{+}$-taurocholate cotransporting polypeptide (NTCP) and OATP2B1 by darolutamide and
Table 1 In vitro analysis of drug transporter inhibition by darolutamide and ketodarolutamide

\begin{tabular}{llll}
\hline Transporter & Substrate/reference inhibitor & $\mathrm{IC}_{50}(\mu \mathrm{M})$ & \\
\cline { 2 - 3 } & & Darolutamide & Keto-darolutamide \\
\hline P-gp & Digoxin/cyclosporin A & 16.4 & 2.6 \\
BCRP & Cladibrine/Ko143 & 1.3 & 0.57 \\
OATP1B1 & Atorvastatin/rifamycin & 16.8 & $>10$ \\
OATP1B3 & Atorvastatin/rifamycin & 39.3 & $>10$ \\
OATP1B1 (with pre-incubation) & Pravastatin/rifamycin & 3.8 & 3.0 \\
OATP1B3 (with pre-incubation) & Pravastatin/rifamycin & 5.0 & 14.2 \\
OAT1 & PAH/probenecid & $>50$ & $>2$ \\
OAT3 & Furosemide/probenecid & 4.5 & $>2$ \\
OCT1 & ${ }^{3}$ H-MPP ${ }^{+} /$decynium 22 & $>50$ & $>10$ \\
OCT2 & ${ }^{3}$ H-MPP ${ }^{+} /$imipramine & $>50$ & $>2$ \\
BSEP & Taurocholic acid/cyclosporin & $>60$ & $>300^{\mathrm{a}}$ \\
MRP2 & CDCF/benzbromarone & $>50$ & $>10$ \\
MATE1 & Metformin/cimetidine & 32.3 & $>10$ \\
MATE2 K & Metformin/pyrimethamine & 9.5 & 3.0 \\
OATP2B1 & Estrone 3-sulfate/glibenclamide & $>50$ & $>10$ \\
NTCP & Estrone 3-sulfate/cyclosporin A & $>50$ & $>10$ \\
\hline
\end{tabular}

$B C R P$ breast cancer resistance protein, $B S E P$ bile salt export pump, $C D C F 5(6)$ carboxy $2^{\prime}, 7^{\prime}$ dichlorofluorescein, $I C_{50}$ concentration required for $50 \%$ inhibition, $M P P 1$ methyl 4 phenylpyridinium, MRP 2 multidrug resistance protein 2, MATE multidrug and toxin extrusion, $N T C P$ sodium/taurocholate cotransporting polypeptide, $O A T$ organic anion transporter, $O A T P$ organic anion-transporting polypeptide, $O C T$ organic cation transporter, $P A H$ para aminohippuric acid, $P$ - $g p$ P-glycoprotein

${ }^{a}$ Higher test concentration possible because of the addition of protein to the assay media 
Table 2 In vitro analysis of CYP isoform inhibition by darolutamide, its diastereomers $(S, R)$-darolutamide and $(S, S)$-darolutamide, and ketodarolutamide in human liver microsomes using standard substrates

\begin{tabular}{|c|c|c|c|c|c|c|}
\hline \multirow[t]{2}{*}{ CYP isoform } & \multirow[t]{2}{*}{ Substrate } & \multicolumn{2}{|l|}{$\mathrm{IC}_{50}(\mu \mathrm{M})$} & \multirow[t]{2}{*}{ Substrate } & \multicolumn{2}{|l|}{$\mathrm{IC}_{50}(\mu \mathrm{M})$} \\
\hline & & Darolutamide & $\begin{array}{l}\text { Keto-daroluta- } \\
\text { mide }\end{array}$ & & $\begin{array}{l}(S, R) \text {-darolu- } \\
\text { tamide }\end{array}$ & $\begin{array}{l}(S, S) \text { - } \\
\text { daroluta- } \\
\text { mide }\end{array}$ \\
\hline $1 \mathrm{~A} 2$ & Phenacetin & $>100$ & $>100$ & Phenacetin & $>50$ & $>50$ \\
\hline $2 \mathrm{~A} 6$ & Coumarin & $>100$ & $>100$ & Coumarin & $>50$ & $>50$ \\
\hline 2B6 & Bupropion & $>100$ & 54.2 & Bupropion & $>50$ & $>50$ \\
\hline $2 \mathrm{C} 8$ & Paclitaxel & $>100$ & 48.6 & Amodiaquine & 36.2 & 46.3 \\
\hline $2 \mathrm{C} 9$ & Diclofenac & 30.3 & 9.6 & Diclofenac & 22.6 & $>50$ \\
\hline $2 \mathrm{C} 19$ & $S$-Mephenytoin & 64.1 & 39.5 & $S$-Mephenytoin & 46.7 & $>50$ \\
\hline 2D6 & Bufuralol & 81.9 & 51.9 & Dextromethorphan & $>50$ & 40.2 \\
\hline $2 \mathrm{E} 1$ & Chlorzoxazone & $>100$ & $>100$ & Chlorzoxazone & $>50$ & $>50$ \\
\hline $3 \mathrm{~A} 4$ & Midazolam & $>100$ & $>50$ & Midazolam & $>50$ & $>50$ \\
\hline 3A4 (with pre-incubation) & Midazolam & $>100$ & $>50$ & Midazolam & $>50$ & $>50$ \\
\hline $3 \mathrm{~A} 4$ & Testosterone & $>100$ & $>50$ & Testosterone & $>50$ & $>50$ \\
\hline 3A4 (with pre-incubation) & Testosterone & $>100$ & $>50$ & Testosterone & $>50$ & $>50$ \\
\hline
\end{tabular}

CYP cytochrome $\mathrm{P} 450, I C_{50}$ concentration required for $50 \%$ inhibition

keto-darolutamide was evaluated in transfected HEK cells overexpressing the respective transporter. In addition, experiments including 1-h preincubation were performed for OATP transporters. The probe substrate and reference inhibitors used are listed in Table 1. Generally, cells were incubated with probe substrate, and the $\mathrm{IC}_{50}$ was determined in the absence and presence of darolutamide and ketodarolutamide at concentrations of $\leq 50 \mu \mathrm{M}$ and $\leq 10 \mu \mathrm{M}$, respectively.

\subsection{Phase I Clinical Studies}

\subsubsection{Study Design and Subjects}

Three phase I studies were conducted as prospective, open-label, nonrandomized, fixed-sequence studies in healthy volunteers (NCT03048110, NCT03237416 and NCT02671097). To be eligible, subjects were required to be healthy, aged $45-65$ years with a body mass index of $\geq 18$ and $\leq 29.9$ or $\leq 30 \mathrm{~kg} / \mathrm{m}^{2}$. Darolutamide $600 \mathrm{mg}$ was administered orally as two $300 \mathrm{mg}$ tablets; this dose was based on the ARADES study [4], and the pharmacokinetics of darolutamide are linear at this dose. The bioanalytical methods used are summarized in the Supplementary Methods section of the Supplementary Materials.

The studies were conducted in accordance with the Declaration of Helsinki and the International Conference on Harmonisation guideline for Good Clinical Practice. All subjects provided informed consent before any study procedures or assessments were performed.

\subsubsection{Study with Strong CYP3A4/P-gp and BCRP Inhibitor and CYP3A4/P-gp Inducer}

The effects of itraconazole and rifampicin on the pharmacokinetics of darolutamide, its diastereomers and ketodarolutamide were investigated in a trial with a three-period design (Fig. 1a). Darolutamide $600 \mathrm{mg}$ and itraconazole $200 \mathrm{mg}$ twice daily were administered with food to enhance the absorption of darolutamide and achieve the maximum inhibitory effect of itraconazole, whereas rifampicin $600 \mathrm{mg}$ once daily was dosed in the fasted state (after an overnight fast of $\geq 10 \mathrm{~h}$ prior to morning dosing or after a 2 -h fast prior to evening dosing) as food decreases its absorption and simultaneous administration is not necessary for induction.

\subsubsection{Studies with CYP3A4 and Drug Transporter Substrates}

Both trials evaluating potential perpetrator effects of darolutamide followed a two treatment period design. In the first study, the effects of darolutamide on the sensitive CYP3A4 substrate, midazolam, and the intestinal P-gp substrate, nonconjugated dabigatran etexilate, were investigated (Fig. 1b). Midazolam $1 \mathrm{mg}$ and dabigatran etexilate $75 \mathrm{mg}$ were administered together as a 'cocktail' because no interaction between the two substrates was expected [15]. A second study evaluated the effects of darolutamide $600 \mathrm{mg}$ twice daily on the pharmacokinetics of rosuvastatin, a substrate for BCRP, OATP1B1, OATP1B3 and OAT3 (Fig. 1c); including follow-up, total study duration was approximately 9 weeks. 


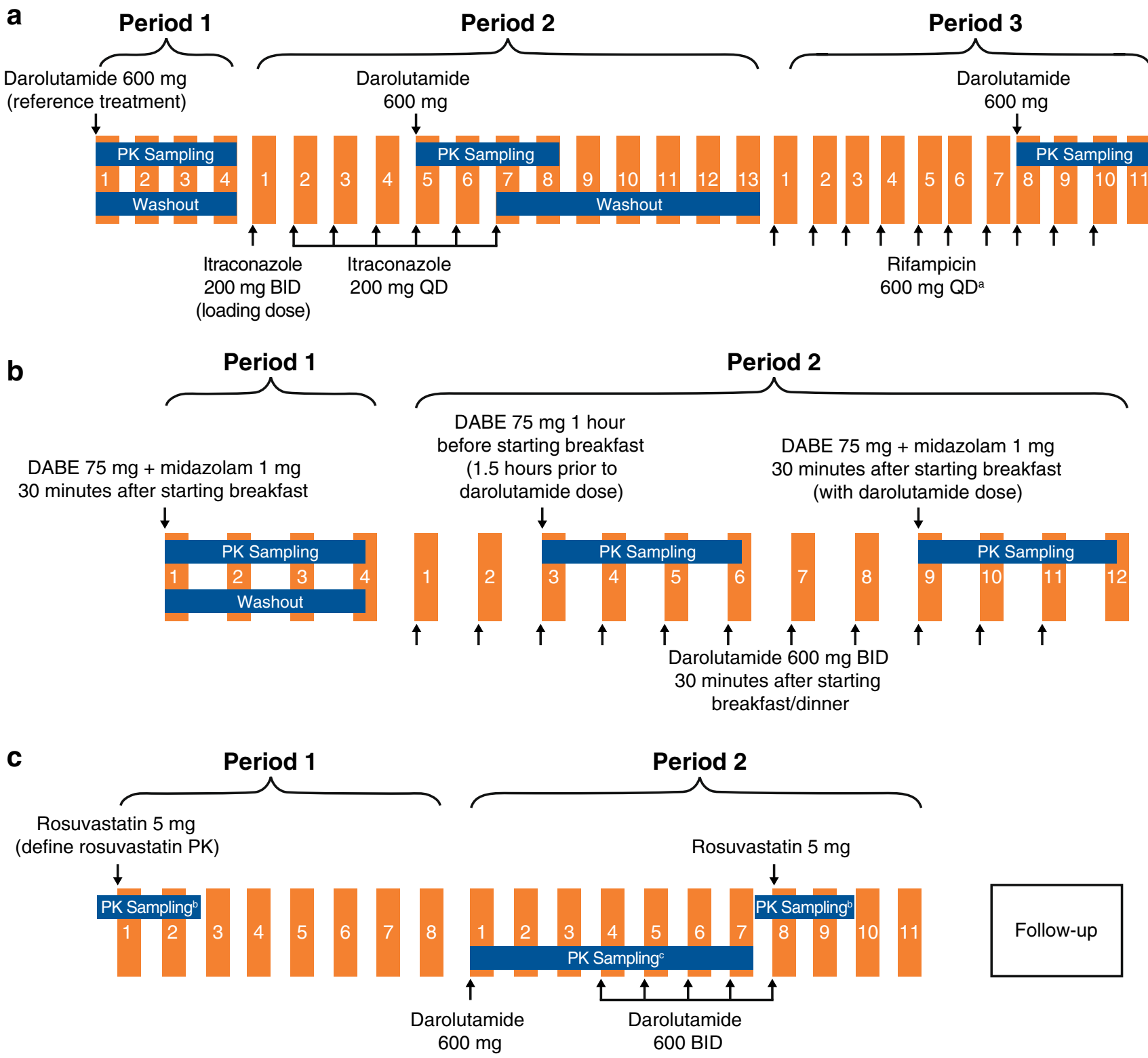

Fig. 1 Study design of the phase I clinical trials with a a strong CYP3A4/P-gp and BCRP inhibitor and a CYP3A4/P-gp inducer, b CYP3A4 and P-gp substrates and $\mathbf{c}$ a substrate for BCRP, OATP1B1, OATP1B3 and OAT3. 'Dosed in the morning on days 1-10, except for day 8 when subjects received a single dose of darolutamide $600 \mathrm{mg}$ in the morning and rifampicin $600 \mathrm{mg} 12 \mathrm{~h}$ later; ${ }^{\mathrm{b}}$ plasma and

Rosuvastatin $5 \mathrm{mg}$ was administered with food; food intake has been shown to reduce rosuvastatin bioavailability [16].

\subsubsection{Pharmacokinetic Analyses}

Blood and urine samples for the assessment of the potential impact of DDIs on the pharmacokinetics of darolutamide or co-administered drugs were obtained according to schedules defined for each study (Fig. 1, Table S2). The main pharmacokinetic parameters included: area under the curve (AUC), urine sampling to evaluate the PK of rosuvastatin; ${ }^{\text {cplasma sampling }}$ to evaluate the PK of darolutamide, its diastereomers and keto-darolutamide. $B C R P$ breast cancer resistance protein, $B I D$ twice daily, $C Y P$ cytochrome P450, DABE dabigatran etexilate, $P$ - $g p$ P-glycoprotein, $P K$ pharmacokinetic(s), $Q D$ once daily

maximum plasma concentration $\left(C_{\max }\right)$, terminal elimination half-life $\left(t_{1 / 2}\right)$ and time to $C_{\max }\left(t_{\max }\right)$. In the rosuvastatin study, the renal clearance $\left(\mathrm{CL}_{\mathrm{R}}\right)$ of rosuvastatin was also calculated.

\subsubsection{Pharmacokinetic and Statistical Analysis}

Pharmacokinetic parameters were calculated by noncompartmental analysis (WinNonlin, version 5.3, Pharsight Corp.) in conjunction with the Automation Extension 
(WinAE version 2.90, Bayer Pharma AG). To evaluate the potential effect of itraconazole and rifampicin on the pharmacokinetics of darolutamide and its diastereomers as well as the major metabolite keto-darolutamide, the logarithms of $\mathrm{AUC}_{(0-72)}$ and $C_{\max }$ of the respective compounds were analyzed using linear mixed effect models. To evaluate the potential effect of darolutamide on the pharmacokinetics of rosuvastatin, midazolam and dabigatran etexilate, the logarithms of AUC and $C_{\max }$ of the respective compounds were analyzed using linear mixed effect models.

\subsubsection{Safety}

All treatment-emergent adverse events (AEs) and drugrelated AEs occurring in the period between the signing of the informed consent and the end of follow-up were recorded in all three studies. After the end of follow-up, serious adverse events (SAEs) were reported if the investigator considered the event was possibly caused by participation in the study.

\section{Results}

\subsection{In Vitro Evaluations}

\subsubsection{Metabolizing Enzymes}

In vitro, darolutamide was predominantly metabolized via oxidative biotransformation catalyzed by CYP3A4 to form the major circulating metabolite keto-darolutamide. In healthy volunteers, $30 \%$ of darolutamide clearance was attributed to CYP3A4 metabolism (data on file). CYP1A1, AKR1C3, alcohol dehydrogenase and carbonyl reductase contributed to darolutamide metabolism to a minor extent. Both diastereomers underwent similar oxidative biotransformation mediated by CYP3A4. In hepatocytes, keto-darolutamide was reconverted to darolutamide, with preferred formation of $(S, S)$-darolutamide, catalyzed by cytosolic reductases-mainly AKR1C3, with a minor role for AKR1D1 (the involvement of multiple enzymes in the metabolism of darolutamide will be presented in detail elsewhere). Keto-darolutamide is also a substrate for further CYP3A4-mediated oxidation.

O-glucuronidation mediated predominantly by UGT1A9 also contributed to the metabolism of darolutamide, with UGT1A8, UGT2B17, UGT1A3 and UGT1A1 involved to a lesser degree. However, as several pathways contributed to the overall clearance of approximately $30 \%$ of darolutamide (data on file), the risk of clinically relevant DDIs with concomitant UGT inhibitors is considered to be low.

\subsubsection{Substrate Characteristics for Drug Transporters}

The efflux ratios for darolutamide at concentrations of $0.5,2$ and $10 \mu \mathrm{M}$ in Caco-2 cells were 78, 98 and 14, respectively. At the concentration of $2 \mu \mathrm{M}$ darolutamide, efflux ratios were markedly lower in Caco- 2 cells with reduced expression levels of P-gp or BCRP compared with wildtype cells (3.6 or 36, respectively). The corresponding relative efflux ratios (in wildtype Caco-2 cells over those with reduced P-gp or BCRP expression) were 27 and 2.7, respectively. Both efflux ratios and relative efflux ratios exceeded the threshold of 2 for significant efflux, suggesting that darolutamide is a substrate for P-gp and BCRP. However, the reduced efflux ratio at the highest test concentration indicates saturation of efflux transport at clinically relevant intestinal concentrations. Experiments in MDCK cells also revealed that efflux ratios for darolutamide and keto-darolutamide were $>2$ and were reduced in the presence of a BCRP-specific inhibitor (Ko143). Based on these in vitro data, darolutamide was classified as a P-gp and BCRP substrate. However, efflux ratios suggest that darolutamide is a more sensitive substrate for P-gp than for BCRP.

In OATP1B1- and OATP1B3-transfected HEK cells, uptake of darolutamide was similar to that in vector control cells. The uptake rates of darolutamide were not inhibited by rifampicin (an OATP inhibitor), indicating that darolutamide is not a substrate for these hepatic uptake transporters. There was also no uptake of darolutamide or keto-darolutamide in OCT1-transfected HEK cells, and uptake rates were not affected by decynium-22 (an OCT1 inhibitor).

\subsubsection{Inhibition of Enzymatic Activity by Darolutamide}

The enzymatic activity of CYP1A2, 2A6, 2B6, 2C8, 2C9, 2C19, 2D6, 2E1 and 3A4 measured using standard substrates was not affected or only slightly inhibited in vitro in the presence of darolutamide, its diastereomers or its metabolite (Table 2). The lowest $\mathrm{IC}_{50}$ was $22.6 \mu \mathrm{M}$ observed for CYP2C9 in the presence of $(S, R)$-darolutamide (Table $\mathrm{S} 2$ ). This indicates that CYP2C9 is the isoform most sensitive to inhibition by darolutamide, its diastereomers or its metabolite. However, as the inhibitory concentration is higher than the plasma concentration of unbound darolutamide $[<0.6 \mu \mathrm{M}$ for $(S, R)$ - and $(S, S)$-darolutamide], the inhibition potential of darolutamide is weak. When midazolam and testosterone were applied as CYP3A4 substrates, time-dependent inhibition was not observed (Table 2). When DDI risk was assessed with the rank order approach and mechanistic static model suggested by regulatory authorities, clinically relevant pharmacokinetic DDIs through inhibition of CYP isoforms were found to be unlikely at plasma concentrations expected for darolutamide. 
In vitro, $(S, R)$-darolutamide did not notably inhibit activities of UGT1A4, 1A6 or 2B7. Applying a rank order approach, $(S, R)$-darolutamide exhibited the most inhibitory effect on UGT1A9 $\left(\mathrm{IC}_{50}=12.5 \mu \mathrm{M}, \mathrm{Ki}=6.32 \mu \mathrm{M}\right)$ followed by UGT1A1 $\left(\mathrm{IC}_{50}=26.5 \mu \mathrm{M}\right)$. The only notable inhibition of UGT isoforms by $(S, S)$-darolutamide was of UGT1A1 activity $\left(\mathrm{IC}_{50}=31.7 \mu \mathrm{M}\right)$. While keto-darolutamide did not appreciably alter activities of UGT1A4, 1A6, 1A9 and 2B7, an inhibitory effect was observed on UGT1A1 $\left(\mathrm{IC}_{50}=6.41 \mu \mathrm{M}\right.$, $\mathrm{Ki}=8.13 \mu \mathrm{M})($ Table S3).

\subsubsection{Induction of CYP1A2, CYP2B6 and CYP3A4}

In in vitro hepatocyte cultures, there was no relevant induction of CYP1A2 or CYP2B6 with darolutamide, its diastereomers or keto-darolutamide (indicated by maximal fold induction of $<2$-fold). However, darolutamide resulted in concentration-dependent induction of CYP3A4 enzymatic activity with $\leq 5.3$-fold ( $28 \%$ of rifampicin response) induction, with similar results observed for its diastereomers. For keto-darolutamide, an increase of CYP3A4 activity of $\leq 5$.4fold was seen. Based on application of the RIS method, darolutamide and its diastereomers were predicted to be moderate-to-strong inducers of CYP3A4, and keto-darolutamide was predicted to be a weak-to-moderate inducer for the sensitive CYP3A4 substrate, midazolam, reducing its AUC by $\leq 50-84 \%$ (Table S4). However, due to the interconversion of darolutamide and keto-darolutamide, the induction effect observed in vitro cannot be attributed specifically to either darolutamide (or one of its diastereomers) or keto-darolutamide. Thus, the clinical effect of darolutamide on midazolam could be anywhere from a weak to a strong reduction in plasma exposure.

\subsubsection{Inhibition of Efflux and Uptake Transporters}

In Caco-2 cells, concentration-dependent inhibition of drug transport mediated by P-gp (digoxin efflux) and by BCRP (cladribine efflux) was observed with darolutamide, with $\mathrm{IC}_{50}$ values of $16.4 \mu \mathrm{M}$ and $1.3 \mu \mathrm{M}$, respectively (Table 2; Fig. S1). In MDCK cells, keto-darolutamide showed inhibitory potential toward P-gp- and BCRP-mediated transport with $\mathrm{IC}_{50}$ values of $2.6 \mu \mathrm{M}$ and $0.6 \mu \mathrm{M}$, respectively. Moreover, darolutamide inhibited transport of the MATE1 K and MATE2-K substrate metformin with $\mathrm{IC}_{50}$ values of $32.3 \mu \mathrm{M}$ and $9.5 \mu \mathrm{M}$, respectively. Similar inhibitory effects were observed with keto-darolutamide. Neither darolutamide nor keto-darolutamide showed inhibitory effects toward BSEP or MRP2.

Inhibition of OATP1B1- and OATP1B3-mediated uptake of atorvastatin in transporter-transfected HEK cells was observed with darolutamide, with $\mathrm{IC}_{50}$ values of $16.8 \mu \mathrm{M}$ and $39.3 \mu \mathrm{M}$, respectively, when cells were simultaneously incubated with both compounds. Preincubation of the cells with darolutamide, however, resulted in lower $\mathrm{IC}_{50}$ values of $3.8 \mu \mathrm{M}$ and $5.0 \mu \mathrm{M}$. For keto-darolutamide, preincubation led to $\mathrm{IC}_{50}$ values of $3.0 \mu \mathrm{M}$ and $14.2 \mu \mathrm{M}$, respectively (previously, no $\mathrm{IC}_{50}$ values were reached due to solubility limitations). For OAT3-mediated uptake of furosemide, the $\mathrm{IC}_{50}$ value for darolutamide was $4.5 \mu \mathrm{M}$. Inhibition $>50 \%$ of uptake transporters OAT1, OCT1, OCT2, OATP2B1 and NTCP was not observed with darolutamide. Ketodarolutamide showed no inhibitory potential toward uptake transporters, with the exception of OATP transporters after preincubation.

\subsection{Phase I Clinical Studies}

\subsubsection{Impact of Co-administered Drugs on the Pharmacokinetic Profile of Darolutamide}

Since in vitro studies identified darolutamide as a substrate for CYP3A4 metabolism and P-gp and BCRP efflux transport, the impact of co-administering inhibitors and inducers of these pathways was evaluated in a phase I clinical study. Co-administration of darolutamide with a strong CYP3A4, P-gp and BCRP inhibitor (itraconazole) and a CYP3A4 and P-gp inducer (rifampicin) was investigated in 15 male subjects. All enrolled subjects received study treatment as planned and were included in the pharmacokinetic and safety analyses. Demographic and baseline characteristics are summarized in Table 3.

Concomitant administration of itraconazole resulted in increased darolutamide exposure (1.7-fold), while coadministration of rifampicin led to a $72 \%$ decrease in darolutamide exposure (Fig. 2, Table S5). Results were similar for the diastereomers and keto-darolutamide. Overall, treatment with darolutamide given alone or in combination with the CYP3A4, P-gp and BCRP inhibitor itraconazole or the CYP3A4 and P-gp inducer rifampicin (both at steady state) was safe and well tolerated.

\subsubsection{Impact of Darolutamide on the Pharmacokinetic Profiles of Co-administered Drugs}

3.2.2.1 CYP3A4 and P-gp Substrates The induction potential for CYP3A4 and inhibition potential for P-gp by darolutamide and keto-darolutamide was evaluated in a phase I study. All 15 subjects who received study treatment were included in the safety analysis, whereas two subjects did not have valid pharmacokinetic profiles and were excluded from the pharmacokinetic analysis. Demographic and baseline characteristics are summarized in Table 3.

Co-administration of darolutamide led to reductions in AUC and $C_{\max }$ of the sensitive CYP3A4 substrate, midazolam, of approximately $29 \%$ and $32 \%$, respectively, versus 
midazolam alone. Co-administration of the P-gp substrate, dabigatran etexilate and darolutamide reduced non-conjugated dabigatran AUC and $C_{\max }$ by $9 \%$ and $16 \%$, respectively (Table S5). The $t_{\max }$ and $t_{1 / 2}$ for both midazolam and non-conjugated dabigatran were comparable in the presence and absence of darolutamide. Hence, darolutamide showed only weak CYP induction and no P-gp inhibition potential (Figs. 3, 4). No safety concerns were identified when darolutamide was administered concomitantly with dabigatran etexilate or midazolam to healthy male volunteers.

3.2.2.2 Substrate for BCRP, OATP1B1, OATP1B3 and OAT3: Rosuvastatin Preclinical studies indicated that darolutamide may inhibit transporters, with substrates of BCRP, OAT3, OATP1B1 and OATP1B3 expected to be most clinically relevant. These include statins, which are common comedications in patients with prostate cancer. As rosuvastatin is a substrate for all these transporters, the perpetrator effects of darolutamide on rosuvastatin were investigated in a phase I study in 30 healthy subjects. All subjects received treatment as planned and were included in the safety analysis. Demographic and baseline characteristics are summarized in Table 3.

Plasma $\mathrm{AUC}_{(0-24)}$ and $C_{\text {max }}$ of rosuvastatin were approximately fivefold higher when administered with darolutamide compared with rosuvastatin alone (Fig. 4), but comedication with darolutamide did not affect $t_{\max }$ [median 4.00 (2.00-6.03) $\mathrm{h}$ with rosuvastatin alone versus 4.07 (2.48-8.00) h with rosuvastatin plus darolutamide] or $t_{1 / 2}$ of rosuvastatin, indicating that plasma clearance is unchanged (Fig. 5, Table S5). Similarly, the ratio of $\mathrm{CL}_{\mathrm{R}}$ during rosuvastatin and darolutamide co-administration versus $\mathrm{CL}_{\mathrm{R}}$ for rosuvastatin treatment alone was 0.97 , and the $90 \%$ CIs of $(0.89,1.06)$ were within the range of $(0.80,1.25)$ accepted for bioequivalence, indicating that darolutamide has no effect on renal clearance of rosuvastatin and thus no likely effect on OAT3. Rosuvastatin exerted no clinically relevant effects on darolutamide exposure (including its diastereomers and keto-darolutamide; Fig. S2). The incidence of treatment-emergent AEs related to single doses of rosuvastatin
$5 \mathrm{mg}$ was similar when administered alone or with concomitant darolutamide.

\section{Discussion}

As a novel agent intended for use in men with prostate cancer, a population with high comedication use for comorbidities [10, 17], it is important to evaluate the risk of clinically relevant DDIs with darolutamide. In the phase III ARAMIS study in men with nmCRPC, $>98 \%$ of patients were receiving at least one concomitant medication, and multiple medication use was common [18], consistent with other reports [19].

In vitro testing indicated that oxidative metabolism of darolutamide is predominantly catalyzed by CYP3A4. Other metabolizing enzymes (e.g., UGT) are involved, but the level of contribution renders inhibitors or inducers of these enzymes unlikely to result in clinically relevant DDIs with darolutamide. Consistent with the observation that darolutamide is a CYP3A4 substrate, phase I clinical data showed that darolutamide exposure was increased 1.7-fold when coadministered with the strong CYP3A4 inhibitor itraconazole $200 \mathrm{mg} /$ day. However, the increase in darolutamide AUC is low when compared with increases of $\geq 5$-fold when a sensitive CYP3A4 substrate (e.g., midazolam, lovastatin) is co-administered with a strong CYP3A4 inhibitor [20-22]. When administered at a low dose of $100 \mathrm{mg}$ /day for 4 days, itraconazole was reported to increase lovastatin AUC 15-fold [20]. Hence, the degree of increased exposure for darolutamide suggests weak sensitivity to CYP3A4 inhibition. Consistent with this observation, data from a covariate analysis within a population pharmacokinetic model based on the phase III ARAMIS clinical trial indicated that co-administration of CYP3A4 inhibitors, which were taken on the same day as darolutamide blood sampling, had no significant impact on the pharmacokinetics of darolutamide [18].

Preclinical data indicated that darolutamide is likely to be a substrate for the efflux transporters P-gp and BCRP. Consequently, strong inhibitors of P-gp or BCRP may be expected to alter the pharmacokinetics of darolutamide. As
Table 3 Demographics and baseline characteristics of participants (healthy Caucasian volunteers) in the phase I studies

\begin{tabular}{lccc}
\hline Characteristic & $\begin{array}{l}\text { CYP3A4/P-gp inhibitor and } \\
\text { CYP3A4 inducer }(N=15)\end{array}$ & $\begin{array}{l}\text { CYP3A4 and P-gp sub- } \\
\text { strates }(N=15)\end{array}$ & $\begin{array}{c}\text { Drug transporter } \\
\text { substrate }(N=30)\end{array}$ \\
\hline Male, $n(\%)$ & $15(100)$ & $15(100)$ & $15(50)$ \\
Age $($ years $)$ & $52.4(45-61)$ & $57.5(49-64)$ & $54.9(47-62)$ \\
Weight $(\mathrm{kg})$ & $77.9(69.7-95.5)$ & $77.6(62.5-89.0)$ & $72.9(53.7-100.0)$ \\
Height $(\mathrm{cm})$ & $178(167-190)$ & $174(167-183)$ & $171(155-190)$ \\
BMI $\left(\mathrm{kg} / \mathrm{m}^{2}\right)$ & $24.5(21.1-27.9)$ & $25.6(21.4-29.9)$ & $24.8(20.3-28.8)$ \\
\hline
\end{tabular}

Values presented for the safety population as mean (range) unless stated otherwise $B M I$ body mass index, $C Y P$ cytochrome $\mathrm{P} 450, P$-g $p$ P-glycoprotein 
Fig. 2 Effects of comedications on the PK of darolutamide: changes in exposure parameters (a) and mean plasma concentration-time profiles for singledose $\mathbf{b}$ darolutamide and $\mathbf{c}$ ketodarolutamide alone and with itraconazole or rifampicin in healthy male subjects $(N=15)$. $P K$ pharmacokinetic(s)

a

\section{Population}

Strong CYP3A4 inducer

Rifampicin

$600 \mathrm{mg}$ QD

Strong CYP3A4/P-gp inhibitor Itraconazole $200 \mathrm{mg}$ QD

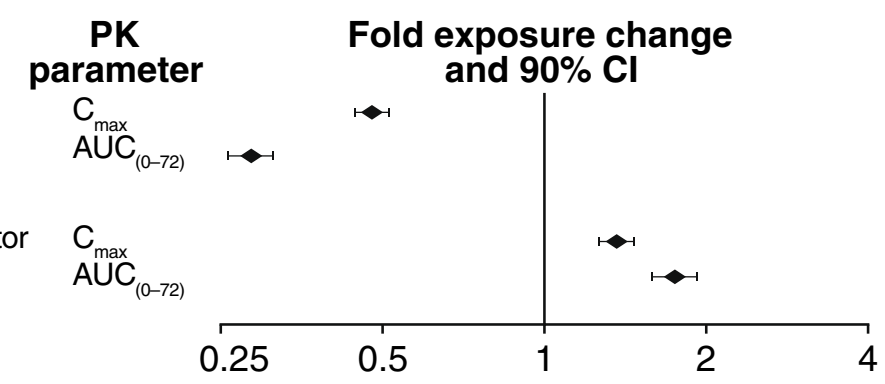

b

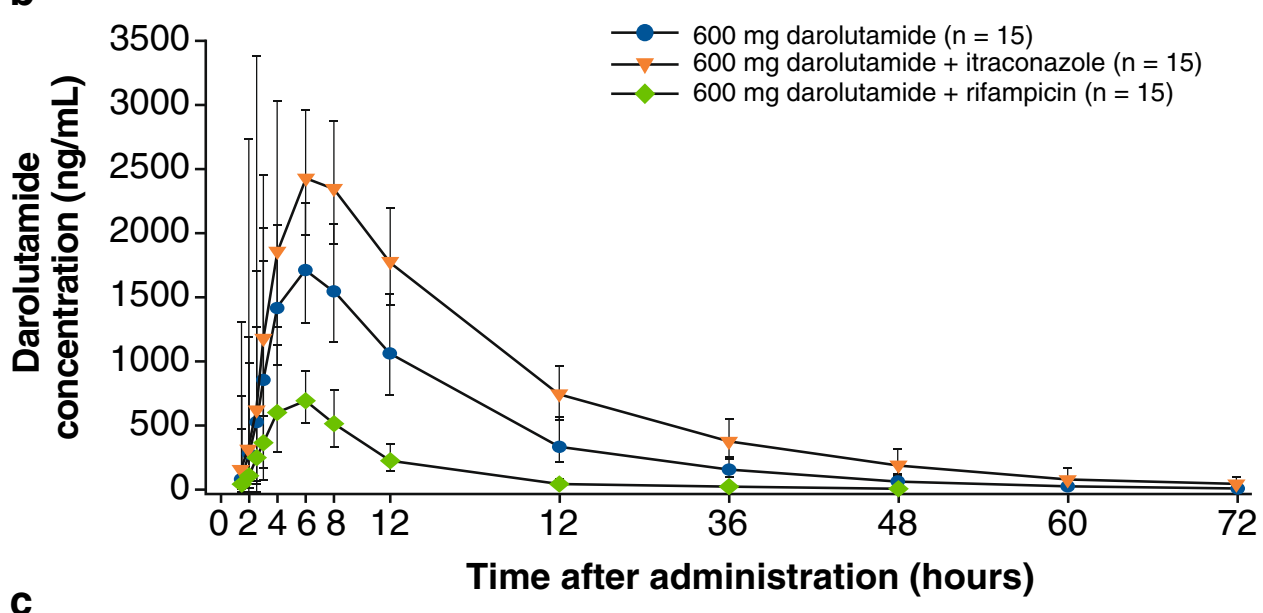

itraconazole inhibits P-gp and BCRP as well as CYP3A4, the 1.7-fold increase in darolutamide exposure observed with co-administered itraconazole may also be attributed to the effects of P-gp and BCRP inhibition. However, given the observed saturation of P-gp-mediated darolutamide transport in a Caco- 2 cell system at test concentrations $(<10 \mu \mathrm{M})$ far below clinically relevant intestinal concentrations with darolutamide $600 \mathrm{mg}$ [ $270 \mu \mathrm{M}$ (data on file)], it is considered unlikely that P-gp would limit darolutamide absorption or that P-gp inhibition contributed to the observed effect. Furthermore, in the covariate analysis conducted during development of the population pharmacokinetics model, neither
P-gp nor BCRP inhibitors had a significant influence on the pharmacokinetics of darolutamide [18].

As a substrate for CYP3A4 darolutamide also has the potential to be affected by CYP3A4 inducers. This was demonstrated when co-administration of a strong CYP3A4 inducer, rifampicin, led to a $72 \%$ reduction in darolutamide exposure in healthy volunteers. This level of AUC reduction suggests that darolutamide may be moderately sensitive to CYP3A4 induction. However, it is important to note that few drugs are strong CYP3A4 inducers (e.g., carbamazepine, phenobarbital, phenytoin, rifampicin), and these agents are not often used in patients with prostate cancer $[10,17$, 

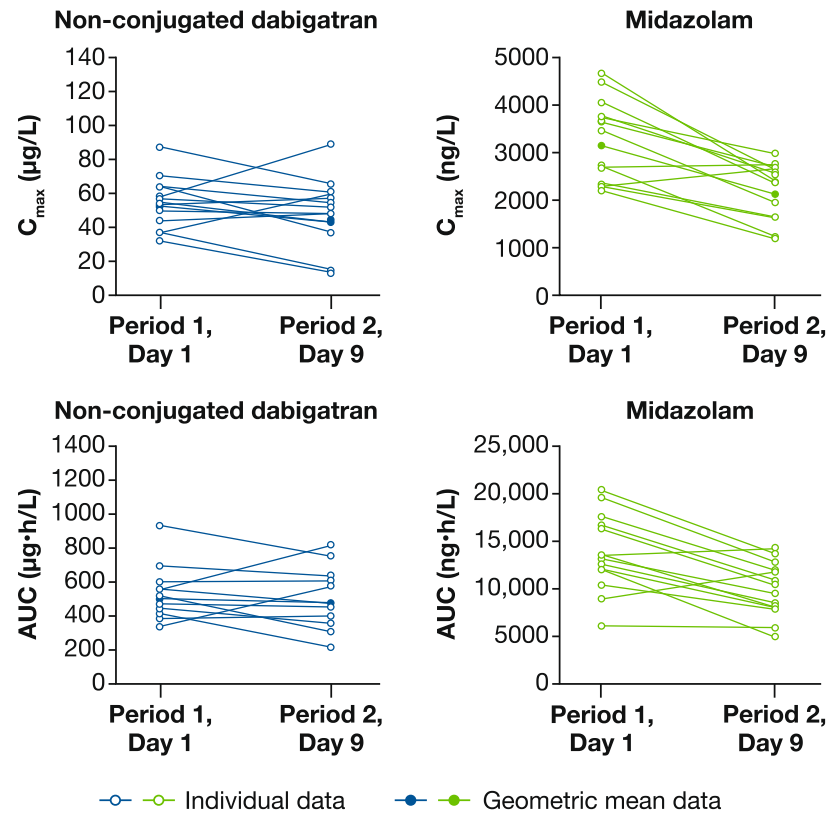

Fig. $3 C_{\max }$ and AUC of non-conjugated DABE and midazolam in the absence (day 1) and presence (day 9) of darolutamide. Data from treatment with DABE $1.5 \mathrm{~h}$ prior to darolutamide (period 2, day 3) are not presented as the results did not differ from those of period 2, day 9. $A U C$ area under the concentration-time curve, $C_{\max }$ maximum observed drug concentration, $D A B E$ dabigatran etexilate

23], so co-administration with darolutamide could easily be avoided.

The impact of darolutamide on the pharmacokinetics of other drugs has been investigated extensively. In vitro findings suggested that darolutamide may inhibit CYP2C9, CYP2C19 and CYP2D6 activity, with no or minimal inhibitory effects on CYP1A2, CYP2A6, CYP2B6, CYP2C8, CYP2E1 and CYP3A4. The lowest in vitro $\mathrm{IC}_{50}$ values were observed for the inhibition of CYP2C9, suggesting that this is the most sensitive CYP enzyme. However, a mechanistic modeling assessment of DDI risk that considers the clinically observed absorption rate of darolutamide indicated that darolutamide is not an inhibitor of CYP2C9 in vivo and is therefore unlikely to inhibit other CYP enzymes
[13]. Similarly, in vitro data suggested that darolutamide may induce CYP3A4 metabolism, but clinical data revealed darolutamide to have only a weak inducing effect on clearance of the sensitive CYP3A4 substrate, midazolam, leading to a $29 \%$ decrease in exposure [24]. This is not considered clinically relevant in line with label information for other sensitive CYP3A4 substrates such as tacrolimus, for which frequent monitoring and dose adjustment are only recommended with co-administration of strong, but not moderate or weak, CYP3A4 inducers [25].

Preclinical evaluation has shown that darolutamide may have the potential to inhibit some drug transporters: intestinal efflux transporters (P-gp, BCRP), hepatic uptake transporters (OATP1B1, OATP1B3) and the active renal elimination transporter OAT3. However, in a phase I clinical study, darolutamide demonstrated no clinically relevant interaction with the P-gp transporter substrate. In another clinical study, co-administration of darolutamide demonstrated a substantial effect on the pharmacokinetics of rosuvastatin, a substrate for BCRP, OATP1B1, OATP1B3 and OAT3 [22], increasing exposure approximately fivefold. Nevertheless, times to reach peak plasma concentration and elimination rate were not affected, indicating that total plasma clearance was unchanged. Given a fraction absorbed $\left(f_{\mathrm{a}}\right)$ of rosuvastatin of 0.5 [26], BCRP inhibition was expected to only lead to a maximum exposure increase of twofold [20]. However, it was noted that rosuvastatin exposure is reduced upon administration with food [16], likely because of a reduction in $f_{\mathrm{a}}$. The observed exposure value of rosuvastatin in the current study is only $34 \%$ of the reported $\mathrm{AUC}_{(0-24)}$ value of $19.2 \mathrm{~h} \mu \mathrm{g} / \mathrm{l}$ following a single dose of $5 \mathrm{mg}$ rosuvastatin to healthy subjects in the fasted condition [27]. This opens up the possibility of a larger dynamic range for exposure increase as a result of BCRP inhibition. In addition, the darolutamide-mediated inhibition of hepatic BCRP, OATP1B1 and OATP1B3 may have contributed to the observed effect. It is, however, difficult to attribute the exact contributions of these transporters and interactions to the overall effect. Taking the unchanged elimination rate of rosuvastatin into account, the exposure increase observed
Fig. 4 Effects of darolutamide on the PK of other medications: changes in exposure. $A U C$ area under the plasma concentration time curve, $A U C$ (0-24) AUC from time 0 to $24 \mathrm{~h}$, $B C R P$ breast cancer resistance protein, $C I$ confidence interval, $C_{\max }$ peak concentration, $C Y P$ cytochrome $\mathrm{P} 450$, $P g$ - $p$ P-glycoprotein, $P K$ pharmacokinetic(s)

\begin{tabular}{ll} 
Substrate & \multicolumn{1}{c}{ PK } \\
& Parameter \\
BCRP substrate & C $_{\max }$ \\
Rosuvastatin & AUC $_{(0-24)}$ \\
CYP3A4 substrate & C $_{\max }$ \\
Midazolam & AUC \\
P-gp substrate & $\mathrm{C}_{\max }$ \\
Non-conjugated dabigatran & AUC
\end{tabular}

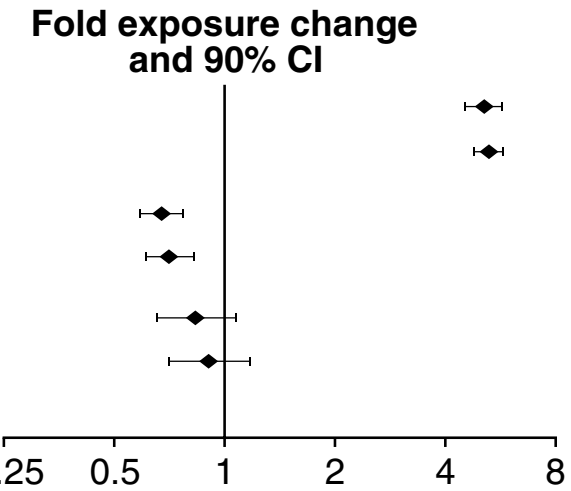




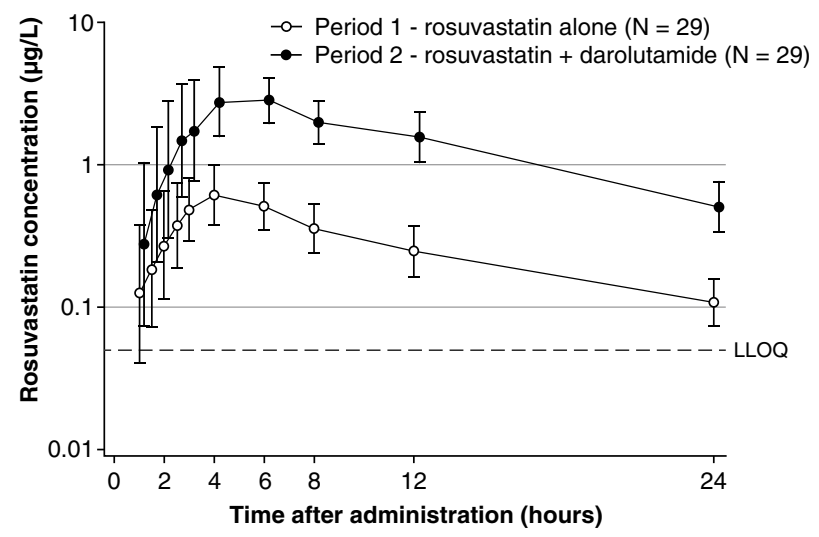

Fig. 5 Mean plasma concentration-time profiles of rosuvastatin in the presence and absence of darolutamide in healthy participants $(N=29)$. A single oral dose of rosuvastatin $5 \mathrm{mg}$ was administered alone in treatment period 1, and a single dose of rosuvastatin $5 \mathrm{mg}$ was administered on day 8 following multiple doses of darolutamide $600 \mathrm{mg}$ BID in treatment period 2. This study included 15 males and 15 postmenopausal females; gender was not found to have a significant effect on pharmacokinetic parameters (data on file). BID twice daily, $L L O Q$ lower limit of quantification $(0.05 \mu \mathrm{g} / \mathrm{l})$

during concomitant darolutamide administration seems to be mainly due to absorption changes of rosuvastatin or the effect of darolutamide on BCRP inhibition. Renal clearance of rosuvastatin remained unchanged after dosing with darolutamide, indicating no clinically relevant effect of darolutamide on OAT3, consistent with in vitro results. Based on current knowledge, the observed effect likely constitutes a worst case scenario for co-administered drugs that are sensitive BCRP and OATP substrates.

In the phase I clinical studies in healthy subjects, darolutamide was safe and well tolerated when administered alone or in combination with single oral doses of dabigatran etexilate, midazolam or rosuvastatin or with multiple doses of itraconazole or rifampicin. There were no clinically relevant changes in the safety profiles of darolutamide or the comedications when administered concomitantly.

Taken together, these in vitro and clinical studies demonstrate that darolutamide has a low potential for DDIs, except for BCRP and probably OATP substrates. Statins are often BCRP and OATP substrates and were used by approximately $30 \%$ of patients with nmCRPC in the phase III ARAMIS study. In these patients, there were no significant differences in AEs between groups in patients receiving darolutamide or placebo in addition to usual care despite equally high use of concomitant medications in each group [18]. In a safety subgroup analysis in statin users and non-users, no imbalance between the darolutamide and placebo arms was observed that might be attributed to DDIs between darolutamide and statins [28]. While darolutamide has shown low DDI potential, AR inhibitors approved for the treatment of nmCRPC, enzalutamide and apalutamide have demonstrated the potential for DDIs with a range of medications that may require therapy modification, including anticoagulants and opioid analgesics (Table S6) [10, 29-31]. These AR inhibitors have demonstrated DDI potential with metabolizing enzymes as well as efflux and hepatic uptake drug transporters [32-34].

\section{Conclusions}

In vitro studies indicated that darolutamide has low or no inhibitory effects on metabolizing enzymes but the potential for a range of other DDIs. However, in confirmatory phase I clinical trials investigating the DDI potential of darolutamide, only weak effects were observed for co-administration of darolutamide with CYP3A4 and P-gp substrates. Inhibition of BCRP and hepatic uptake transporters was reported in the phase I study of darolutamide co-administered with rosuvastatin, but no clinically relevant impact on the $\mathrm{AE}$ profile was observed in the pivotal phase III ARAMIS study.

In conclusion, darolutamide is a substrate for a variety of absorption and/or elimination pathways (CYP3A4, several UGTs, P-gp and BCRP) and, at therapeutic concentrations, has few inhibitory or inducing interactions with other compounds, with increased exposure of BCRP and probably OATP substrates being the main interaction of note [3]. Therefore, darolutamide is unique among AR-targeted therapies in having demonstrated a low potential for clinically relevant DDIs. Minimizing DDIs is expected to reduce complications arising from polypharmacy when treating nmCRPC.

Acknowledgements The authors thank the volunteers and all investigators involved in these studies. Päivi Taavitsainen, Orion Pharma, is acknowledged for her contribution to some of the CYP inhibition studies. Julia Lemmen, Bayer, is acknowledged for her input on the conduct of the transporter assays. Katrin Walkamp provided statistical analysis of the phase I studies, and guidance and critical review on statistical aspects of the manuscript. Medical writing support was provided by Tamsin Williamson, and editorial support, including formatting, proofreading and submission, was provided by Beth King and Annabel Ola, all of Scion Medica, London, supported by Bayer AG according to Good Publication Practice guidelines [35]. The sponsor was involved in the study design, collection, analysis and interpretation of data as well as data checking of information provided in the manuscript. However, ultimate responsibility for opinions, conclusions and data interpretation lies with the authors.

\section{Compliance with Ethical Standards}

Funding This trial was supported by Orion Corporation Orion Pharma and Bayer AG.

Conflict of interest Christian Zurth, Robert Fricke, Olaf Prien, Kristina Graudenz, Karsten Denner, Michaela Bairlein, Clemens-Jeremias von Bühler, Gary Wilkinson and Hille Gieschen are employees of Bayer AG. Drs. Zurth, Prien, Denner, Wilkinson and Gieschen are also 
stockholders of Bayer AG. Mikko Koskinen and Timo Korjamo are employees and stockholders of Orion Corporation Orion Pharma.

Ethical approval All procedures performed in studies involving human participants were in accordance with the ethical standards of the institutional and/or national research committees and with the 1964 Helsinki Declaration and its later amendments or comparable ethical standards. The protocols were approved by the Ethics Committee of the State Medical Chamber of Berlin (NCT03048110 and NCT02671097) and the Ethics Committee of the State Medical Chamber of Baden-Württemberg (NCT03237416).

Informed consent Informed consent was obtained from all individual participants in the studies.

Data sharing Availability of the data underlying this publication will be determined according to Bayer's commitment to the EFPIA/PhRMA "Principles for responsible clinical trial data sharing." This pertains to the scope, timepoint and process of data access. As such, Bayer commits to sharing upon request from qualified scientific and medical researchers patient-level clinical trial data, study-level clinical trial data and protocols from clinical trials in patients for medicines and indications approved in the United States (US) and European Union (EU) as necessary for conducting legitimate research. This applies to data on new medicines and indications that have been approved by the EU and US regulatory agencies on or after January 1, 2014. Interested researchers can use http://www.clinicalstudydatarequest.com to request access to anonymized patient-level data and supporting documents from clinical studies to conduct further research that can help advance medical science or improve patient care. Information on the Bayer criteria for listing studies and other relevant information is provided in the Study Sponsors section of the portal. Data access will be granted to anonymized patient-level data, protocols and clinical study reports after approval by an independent scientific review panel. Bayer is not involved in the decisions made by the independent review panel. Bayer will take all necessary measures to ensure that patient privacy is safeguarded.

Open Access This article is distributed under the terms of the Creative Commons Attribution-NonCommercial 4.0 International License (http://creativecommons.org/licenses/by-nc/4.0/), which permits any noncommercial use, distribution, and reproduction in any medium, provided you give appropriate credit to the original author(s) and the source, provide a link to the Creative Commons license, and indicate if changes were made.

\section{References}

1. Fizazi K, Smith MR, Tombal B. Clinical development of darolutamide: a novel androgen receptor antagonist for the treatment of prostate cancer. Clin Genitourin Cancer. 2018;16(5):332-40. https://doi.org/10.1016/j.clgc.2018.07.017.

2. US Food and Drug Administration. FDA approves darolutamide for non-metastatic castration-resistant prostate cancer. 2019. https ://www.fda.gov/drugs/resources-information-approved-drugs/fdaapproves-darolutamide-non-metastatic-castration-resistant-prost ate-cancer. Accessed 31 July 2019.

3. Bayer HealthCare Pharmaceuticals Inc. Nubeqa (darolutamide) US prescribing information. 2019. https://www.accessdata .fda.gov/drugsatfda_docs/label/2019/212099Orig1s0001bl.pdf. Accessed 31 July 2019.

4. Fizazi K, Massard C, Bono P, Jones R, Kataja V, James N, et al. Activity and safety of ODM-201 in patients with progressive metastatic castration-resistant prostate cancer (ARADES): an open-label phase 1 dose-escalation and randomised phase 2 dose expansion trial. Lancet Oncol. 2014;15(9):975-85. https://doi. org/10.1016/s1470-2045(14)70240-2.

5. Massard C, Penttinen HM, Vjaters E, Bono P, Lietuvietis V, Tammela TL, et al. Pharmacokinetics, antitumor activity, and safety of ODM-201 in patients with chemotherapy-naive metastatic castration-resistant prostate cancer: an open-label phase 1 study. Eur Urol. 2016;69(5):834-40. https://doi.org/10.1016/j.eurur o.2015.09.046.

6. Fizazi K, Shore N, Tammela TL, Ulys A, Vjaters E, Polyakov S, et al. Darolutamide in nonmetastatic, castration-resistant prostate cancer. N Engl J Med. 2019;380(13):1235-46. https://doi. org/10.1056/NEJMoa1815671.

7. Moilanen AM, Riikonen R, Oksala R, Ravanti L, Aho E, Wohlfahrt G, et al. Discovery of ODM-201, a new-generation androgen receptor inhibitor targeting resistance mechanisms to androgen signaling-directed prostate cancer therapies. Sci Rep. 2015;5:12007. https://doi.org/10.1038/srep12007.

8. Sandmann S, Trummel D, Seidel D, Nubbemeyer R, Gieschen H, Zurth C. Higher blood-brain barrier penetration of [14C]apalutamide and [14C]enzalutamide compared to [14C]darolutamide in rats using whole-body autoradiography. In: ASCO genitourinary cancers symposium; 14-16 February; San Francisco 2019. Abstract 156.

9. Zurth C, Sandmann S, Trummel D, Seidel D, Gieschen H. Bloodbrain barrier penetration of [14C]darolutamide compared with [14C]enzalutamide in rats using whole body autoradiography. J Clin Oncol. 2018;36(6_suppl):345.

10. Benoist GE, van Oort IM, Smeenk S, Javad A, Somford DM, Burger DM, et al. Drug-drug interaction potential in men treated with enzalutamide: mind the gap. Br J Clin Pharmacol. 2018;84(1):122-9. https://doi.org/10.1111/bcp.13425.

11. Bohnert T, Patel A, Templeton I, Chen Y, Lu C, Lai G, et al. Evaluation of a new molecular entity as a victim of metabolic drugdrug interactions-an industry perspective. Drug Metab Dispos. 2016;44(8):1399-423. https://doi.org/10.1124/dmd.115.069096.

12. European Medicines Agency. Guideline on the investigation of drug interactions. 2012. https://www.ema.europa.eu/en/docum ents/scientific-guideline/guideline-investigation-drug-interactio ns_en.pdf. Accessed 20 May 2019.

13. US Food and Drug Administration. Clinical drug interaction studies - study design, data analysis, and clinical implications. Guidance for industry [draft guidance]. 2017. https://www.fda. gov/regulatory-information/search-fda-guidance-documents/clini cal-drug-interaction-studies-study-design-data-analysis-and-clini cal-implications-guidance. Accessed 20 May 2019.

14. US Food and Drug Administration. In vitro metabolism and transporter-mediated drug-drug interaction studies. Guidance for industry [draft guidance]. 2017. https://www.fda.gov/regulatory -information/search-fda-guidance-documents/vitro-metabolism -and-transporter-mediated-drug-drug-interaction-studies-guida nce-industry. Accessed 16 Aug 2019.

15. Prueksaritanont T, Tatosian DA, Chu X, Railkar R, Evers R, Chavez-Eng C, et al. Validation of a microdose probe drug cocktail for clinical drug interaction assessments for drug transporters and CYP3A. Clin Pharmacol Ther. 2017;101(4):519-30. https:// doi.org/10.1002/cpt.525.

16. McLean CC, Teft WA, Morse BL, Gryn SE, Hegele RA, Kim RB. Food effect on rosuvastatin disposition and low-density lipoprotein cholesterol. Clin Pharmacol Ther. 2018;104(3):525-33. https ://doi.org/10.1002/cpt.973.

17. Li H, Hodgson E, Watson L, Shukla A, Nelson JJ. Comorbidities and concomitant medication use in men with prostate cancer or high levels of PSA compared to matched controls: a GPRD 
analysis. J Cancer Epidemiol. 2012;2012:291704. https://doi. org/10.1155/2012/291704.

18. Shore N, Zurth C, Fricke R, Gieschen H, Graudenz K, Koskinen $\mathrm{M}$, et al. Evaluation of clinically relevant drug-drug interactions with darolutamide in the phase 3 ARAMIS trial for patients with nonmetastatic castration-resistant prostate cancer. Targ Oncol. 2019. https://doi.org/10.1007/s11523-019-00674-0.

19. Berger AM, Abernethy AP, Atkinson A, Barsevick AM, Breitbart WS, Cella D, et al. NCCN clinical practice guidelines cancerrelated fatigue. J Natl Compr Cancer Netw. 2010;8(8):904-31.

20. Kivisto KT, Kantola T, Neuvonen PJ. Different effects of itraconazole on the pharmacokinetics of fluvastatin and lovastatin. Br J Clin Pharmacol. 1998;46(1):49-53. https://doi.org/10.104 6/j.1365-2125.1998.00034.x.

21. Olkkola KT, Ahonen J, Neuvonen PJ. The effects of the systemic antimycotics, itraconazole and fluconazole, on the pharmacokinetics and pharmacodynamics of intravenous and oral midazolam. Anesth Analg. 1996;82(3):511-6. https://doi.org/10.1097/00000 539-199603000-00015.

22. US Food and Drug Administration. Drug development and drug interactions: table of substrates, inhibitors and inducers. 2017. https://www.fda.gov/drugs/drug-interactions-labeling/drug-devel opment-and-drug-interactions-table-substrates-inhibitors-andinducers. Accessed 15 Aug 2019.

23. Hansten PD, Horn JR. Top 100 drug interactions 2018. A guide to patient management. 19th ed. Dunnellon: H\&H Publications, LLP; 2018.

24. Zurth C, Graudenz K, Denner K, Vairlein M, Korjamo T, Fricke $\mathrm{R}$, et al. Drug-drug interaction of darolutamide with cytochrome P450 and P-glycoprotein substrates: results from clinical and in vitro studies. In: ASCO genitourinary cancers symposium, San Francisco. 2019.

25. Astellas Pharma US Inc. PROGRAF (tacrolimus) US Prescribing Information. 2018. https://www.accessdata.fda.gov/drugs atfda_docs/label/2019/050708s050,050709s042,210115s002lbl. pdf. Accessed 6 Sept 2019.

26. Martin PD, Warwick MJ, Dane AL, Brindley C, Short T. Absolute oral bioavailability of rosuvastatin in healthy white adult male volunteers. Clin Ther. 2003;25(10):2553-63.
27. Prueksaritanont T, Chu X, Evers R, Klopfer SO, Caro L, Kothare $\mathrm{PA}$, et al. Pitavastatin is a more sensitive and selective organic anion-transporting polypeptide $1 \mathrm{~B}$ clinical probe than rosuvastatin. Br J Clin Pharmacol. 2014;78(3):587-98. https://doi. org/10.1111/bcp.12377.

28. Zurth C, Fizazi K, Fricke R, Gieschen H, Graudenz K, Koskinen $\mathrm{M}$, et al. Assessing the clinical relevance of drug-drug interactions (DDI) with darolutamide (DARO). ESMO Congress; 27 September-1 October; Barcelona, Spain. 2019.

29. Astellas Pharma US Inc. Xtandi (enzalutamide) US prescribing information. 2018. https://www.accessdata.fda.gov/drugsatfda _docs/label/2018/203415s014lbl.pdf. Accessed 11 June 2019.

30. Benoist GE, van Oort IM, Burger DM, Koch BCP, Mehra N, van Erp NP. The combination of enzalutamide and opioids: a painful pitfall? Eur Urol. 2019;75(2):351-2. https://doi.org/10.1016/j. eururo.2018.09.011.

31. Janssen Ortho LLC. Erleada (apalutamide) US prescribing information. 2018. https://www.accessdata.fda.gov/drugsatfda_docs/ label/2018/210951s000lbl.pdf. Accessed 22 July 2019.

32. Gibbons JA, de Vries M, Krauwinkel W, Ohtsu Y, Noukens J, van der Walt JS, et al. Pharmacokinetic drug interaction studies with enzalutamide. Clin Pharmacokinet. 2015;54(10):1057-69. https ://doi.org/10.1007/s40262-015-0283-1.

33. US Center for Drug Evaluation and Research. NDA/BLA clinical pharmacology and biopharmaceutics review NDA 203415 Xtandi (enzalutamide). 2012. https://www.accessdata.fda.gov/drugsatfda _docs/nda/2012/203415Orig1s000ClinPharmR.pdf. Accessed 26 Sept 2018.

34. US Center for Drug Evaluation and Research. NDA/BLA multidisciplinary review and evaluation NDA 210951 Erleada (apalutamide). 2018. https://www.accessdata.fda.gov/drugsatfda_docs/ nda/2018/210951Orig 1 s000MultidisciplineR.pdf. Accessed 26 Sept 2018.

35. Battisti WP, Wager E, Baltzer L, Bridges D, Cairns A, Carswell CI, et al. Good publication practice for communicating company-sponsored medical research: GPP3. Ann Intern Med. 2015;163(6):461-4. https://doi.org/10.7326/M15-0288.

\section{Affiliations}

\section{Christian Zurth $^{1}$ (1) Mikko Koskinen ${ }^{2} \cdot$ Robert Fricke $^{3} \cdot$ Olaf Prien $^{1} \cdot$ Timo Korjamo $^{2} \cdot$ Kristina Graudenz $^{1}$. Karsten Denner $^{1} \cdot$ Michaela Bairlein $^{3} \cdot$ Clemens-Jeremias von Bühler $^{3} \cdot$ Gary Wilkinson $^{1} \cdot$ Hille Gieschen $^{1}$}

Mikko Koskinen

mikko.koskinen@orionpharma.com

Robert Fricke

robert.fricke@bayer.com

Olaf Prien

Olaf.Prien@bayer.com

Timo Korjamo

timo.korjamo@orionpharma.com

Kristina Graudenz

kristina.graudenz@bayer.com

Karsten Denner

karsten.denner@bayer.com
Michaela Bairlein

michaela.bairlein@bayer.com

Clemens-Jeremias von Bühler

clemens-jeremias.vonbuehler@bayer.com

Gary Wilkinson

gary.wilkinson@bayer.com

Hille Gieschen

hille.gieschen@bayer.com

1 Bayer AG, Berlin, Germany

2 Orion Corporation, Orion Pharma, Espoo, Finland

3 Bayer AG, Wuppertal, Germany 